\title{
BREVES CONSIDERAÇÕES ACERCA DOS QUILOMBOS, SUAS ROÇAS E SEUS CONFLITOS NA PROVÍNCIA DE MATO GROSSO (1839-1878)
}

\author{
BRIEF CONSIDERATIONS ABOUT THE QUILOMBOS, \\ THEIR PLANTATIONS AND ITS CONFLICTS IN THE PROVINCE \\ OF MATO GROSSO (1839-1878)
}

José Walter Cracco Junior ${ }^{1}$

\begin{abstract}
RESUMO: Este trabalho preza pela interpretação dos quilombos para além de lugares de resistência negra, indígena e de fugitivos da lei. Temos a intenção de apresentar os sujeitos operantes desse local como protagonistas de suas próprias histórias em que por meio de plantaçóes, pequenos roçados e roças, rotas de solidariedade e assaltos a vilas, proporcionavam o florescimento de uma vida nestes espaços e se faziam serem temidos pelos condutores da "ordem" por conta de sua autossuficiência ou mesmo pela busca por ela. Assim, nossas breves reflexóes, estáo pautadas na leitura de alguns documentos possibilitadores de tais interpretações, além dos referenciais teóricos que nos tangenciaram nesses olhares sobre as fontes.
\end{abstract}

PALAVRAS CHAVES: Quilombos, Roças, Resistência.

ABSTRACT: This text presents an interpretation of the quilombos that goes beyond seeing them as places of black, indigenous resistance or flight of the Law. We intend to show the inhabitants of the quilombos as protagonists of their own stories through the raising of small crop plantations, routes of solidarity and house robberies in villages. Activities such as these provided the flourishing of life in these spaces and they reached to be feared by operators of "order", because their self-sufficiency, or at least the search for it. So, our brief reflections are based upon close reading of documents that enable such interpretations, in addition to the theoretical literature that oriented our perspectives on the sources.

KEY-WORDS: Quilombos, Plantations, Resistence.

\section{INTRODUÇÃO}

Os defensores da ordem estabelecida tendem a qualificar as ideias "subversivas" de impraticáveis e irrealistas, o que aliás não os impede de combatê-las com um ardor que só se justifica pelo medo de que elas possam ser realizadas a qualquer momento (JERZY SZACHI, 1972, p.4).

Graduando em História pela Universidade Federal de Mato Grosso do Sul, campus Três Lagoas - UFMS/CPTL. Email: ze ufms@hotmail.com 
Jerzy Szachi tem toda razão quando diz que o medo move a repressão dos defensores da ordem contra os autores das ideias ditas subversivas, neste caso, os oprimidos por eles. Porém, por serem oprimidos esses sujeitos não deixam de falar, ou mesmo sussurrar. Ainda na condição em que, muitas vezes não escrevam/formalizem sua história no papel; são justamente os opressores que a escrevem. Assim, percebemos a necessidade de narrar a história com a lupa voltada a esses sujeitos.

O nosso locus neste estudo é o quilombo seguido dos roçados. Desta forma, este artigo tem por intuito proporcionar uma breve abordagem dos quilombos, apresentando os seus conflitos com o poder provincial e a sua relaçáo com alguns "sujeitos ilustres" que, de maneira direta ou indireta, os cadenciava. Assim como abordar os roçados e o comércio desenvolvido pelos quilombos, ou melhor, pelos agentes sociais presentes nos quilombos na província de Mato Grosso entre os anos de 1839-1878.

O recorte temporal que realizamos se justifica a partir das fontes ${ }^{2}$ que encontramos para compilar este trabalho. Além disso, mesmo sendo um marco que quase atravessa todo período imperial, no caso de Mato Grosso oitocentista, não encontramos tantas fontes, aliás, encontramos espalhadas em tais temporalidades elencadas acima. Portanto, se faz necessário estender os anos para que possamos investigá-las mais a fundo e suprir, por vezes, as falésias das documentaçóes.

\section{UMA BREVE REFLEXÃO SOBRE OS QUILOMBOS E SEUS SUJEITOS NA PROVÍNCIA DE MATO GROSSO}

No início das investigaçóes logo nos deparamos com as principais dificuldades que o tema engloba: encontrar as fontes que narram esses quilombos no Império, assim como, os referenciais teóricos que tratam de maneira pujante este contexto histórico, sobretudo em Mato Grosso oitocentista.

Nesse sentido, Symanski (2011) nos oferece algumas pistas como o nome de alguns quilombos encontrados na província de Mato Grosso, dentre eles o quilombo da "Serra Azul", "Bicho", "Guaiá-Guaiá". Além disso, conta-nos a respeito de pequenos quilombos encontrados na regiáo do Rio Manso, Casca, Roncador e Jangada. Assim, mesmo com seu trabalho lançando luz a esses quilombos podemos perceber que este cuida somente de dizer os nomes, porém nos propicia indícios de que os quilombos estiveram lá. Para tanto, isso é de grande ajuda, uma vez que precisamos nos debruçar em cada vestígio encontrado nas fontes e passagens de alguns pesquisadores, pois cuidam de nos apresentar um norte para nossas reflexões, sobretudo possíveis locais onde estas fontes estão.

Cabe observar que o contato com as fontes trabalhadas neste artigo derivou do trabalho de digitalizaçáo de parte de documentos, entre os anos de 2009 a 2015, coletados no Arquivo Público de Mato Grosso, por bolsistas, mestrandos da UFGD e de iniciaçáo científica, da UFMS, Campus de Três Lagoas, envolvidos nos projetos do Curso de História, sob orientação da profa. Dra. Maria Celma Borges. De 2009 a 2011 o projeto teve o financiamento da FUNDECT. 
Deste modo, é pertinente encará-los como porta-vozes de um conhecimento histórico que, como sabemos, necessita ser estudado, sobretudo por conta do papel que o comércio, de qualquer expressão, e as roças desempenharam na vida efetiva dos quilombos e quilombolas mato-grossenses. Dito de outra forma, considerando que "os quilombos desenvolveram práticas econômicas integradas às economias locais" (GOMES, 2005, p.382), isso nos possibilita pensar os roçados existentes dentro dos quilombos, pois foi a partir deles que se produzia parte dos alimentos necessários para consumos dos próprios quilombolas e o excedente poderia ser comercializado nas fazendas da redondeza, nas pequenas feiras da cidade, nas quitandas, enfim, em qualquer lugar incumbido de vender ou barganhar gêneros alimentícios.

O período colonial nos ajuda a pensar os quilombos sendo geradores de suas próprias existências, vivências, resistências, enfim, da sua autonomia, como sugere Volpato (1996). Não queremos com isso dizer que os quilombos são semelhantes em tempos diferentes, muito pelo contrário, se configuram como diferentes devido as questóes políticas, regimentos internos, formas como os governos provinciais tratavam à ameaça dos quilombos, entre outros fatores. Todavia, mesmo com suas diferenças Volpato nos alerta que os quilombos "mantinham algumas características gerais" (1993, p.183), principalmente quando consideramos que:

\section{A formação dos quilombos significou muito mais do que apenas escravos fugindo para as matas e tentando escapar das perseguiçóes. Escolhiam locais para se estabelecer, procuravam dominar florestas, reinventaram práticas econômicas e tentavam contato com outros setores da sociedade com os quais pudessem ampliar suas bases econômicas (GOMES, 2005, p. 154).}

Nesse âmbito, a cargo de exemplo, podemos mencionar o quilombo do Quariterêque conforme Volpato (1996), foi autossuficiente por si só na Colônia conseguindo resistir a algumas bandeiras montadas para lhe destroçar até 1795, quando foi extinguido. Diferente do Quariterê que náo conseguiu chegar até o Império, o quilombo do rio Sepotuba, segundo Symanski, "foi o de maior longevidade na história de Mato Grosso, tendo sido formado ainda no período colonial” (2011, p.243), servindo ainda de abrigo para soldados desertores no período da Guerra do Paraguai. De tal forma, podemos aquilatar nossa compreensão e perceber que os espaços dos quilombos foram ocupados também por "livres pobres, desertores, criminosos e cativos marginais ao sistema escravista” (VOLPATO, 1993, p.184). Além, é claro, de povos indígenas.

À vista disso, entendemos que a pesquisa histórica deve ir ao encontro dos sujeitos presentes nestes espaços, pois além dos quilombos, das roças existirem, existem, pois, mulheres e homens, sejam brancos, negros e indígenas que as construíram e as cultivavam nestes espaços. Assim, como nos disse Marc Bloch (2001), o historiador deve farejar o homem nos acontecimentos históricos. Ousaríamos e diríamos que devemos farejar o homem e a mulher. Portanto, estamos imbuídos de entender os acontecimentos a partir de sujeitos protagonistas de suas próprias histórias, uma vez que ao fugirem de seus senhores e senhoras e chegarem aos quilombos, ou mesmo formarem esses quilombos, já estariam, mesmo que de maneira instintiva na luta pela sobrevivência, deixando pegadas de sua história.

Isto posto, entendemos que as histórias dessas pessoas não podem ser ignoradas, até mesmo deixadas serem enterradas aos esquecimentos e ao renegar desses sujeitos pelas 
autoridades imperiais. Devemos, como nos disse Benjamin (1987), escovar a história a contrapelo, neste caso, remanejar este entulho que foi jogado sobre esses sujeitos como "sem razão de ser", ${ }^{3}$ tratados à margem, em que as expedições/bandeiras, poderiam simplesmente destroçá-los, como dito num ofício que ordenava que "80 praças municiados e armados sob o comando do capitão Luciano Pereira de Souza, acompanhado do Tenente Justiniano Cândido da Cunha Barbosa e mais alferes de confiança sigam para bater o quilombo". ${ }^{4}$

À vista disso, devemos também perceber que o que compreendemos desses sujeitos foi relatado pelos letrados que atendiam a classes dominantes da sociedade imperial, seja de representantes do poder central enviados às províncias ou homens fortes do poder municipal, mais precisamente os grandes proprietários de terras ${ }^{5}$. Por conta disso, não podemos nos limitar às correspondências oficiais sem uma análise crítica, devemos ser cautelosos ao ler as fontes e ir problematizando os discursos deslegitimadores que o poder central tentava impor sobre esses sujeitos. Mais do que isso, perceber de que modo esses documentos eram produzidos e a quem se destinavam, quem se beneficiava deles. Como, por exemplo, por que o presidente da província de Mato Grosso, Estevão Ribeiro de Rezende, em 31 de maio de 1839, ordenava que o Sr. Capitão Joaquim da Silva Prado cuidasse de reunir informaçóes sobre um quilombo que, de conhecimento do governo, se situava na região do Rio Manco, perto da fazenda Curral dos Veados, essa, pertencente ao Capitão? ${ }^{6}$

Ora, a resposta pode parecer óbvia, já que poderíamos dizer a que interessava ao Capitáo a extinção do quilombo, pois este ficava perto de suas terras e poderia lhe causar tormentos, como já acusado pelo Presidente na correspondência. No entanto, uma questão nos intrigou: não encontramos respostas do dito Capitão ao Presidente da Província afirmando o cumprimento de suas ordens, muito menos informaçóes que o dito quilombo teria sido "destroçado" pela expedição. Por consequência, isto é cabível de algumas interpretaçóes como a não execução das ordens ou execução parcial, pois, como poderíamos saber se o próprio Capitão não se beneficiava com o quilombo? Seja no sentido de mão de obra ${ }^{7}$ ou no fornecimento de gêneros alimentícios? Como men-

3 Este termo é utilizado por Maria Sylvia de Carvalho Franco em sua obra "Homens livres na ordem escravocrata". Não concordamos com tal afirmação da autora, uma vez que entendemos que não há como afirmar que tais sujeitos históricos, os negros e escravos, não tinham razão de ser. Muito pelo contrário, tem toda razão de ser, mas na visão do colonizador, imbuídos de seus princípios, acabavam "não tendo", muito para justificar o mecanismo da escravidão.

4 DOCUMENTO 253 - EST.08. Ofícios reservados do Presidente da Província de Mato Grosso (1871-1878)

5 Neste momento lembramos das reflexóes de Luiz Felipe de Alencastro (1997) sobre os conflitos e jogos de interesse entre público e privado.

6 Província de Mato Grosso: registro de correspondência oficial com o interior da província, 1838 - 1839. Arquivo Público do Estado de Mato Grosso do Sul, doc.56 e.5, 4393.

7 Considerando que os quilombos abrigavam, em sua maioria, escravos fugidos, estes, segundo Wissenbach (1998), não estavam isentos de serem contratados para prestar serviços remunerados. Nesse sentido, os quilombolas, assim como desenvolviam suas redes comerciais pelas fazendas, sitos e chácaras vendendo gêneros alimentícios, poderiam, ao mesmo tempo, negociar sua mão de obra, dado que muitos dos negros eram hábeis em tarefas como carpintaria, marcenaria, construções, ferreiros, enfim. Assim, levantarmos tal indagação pode nos ajudar a pensar algumas açóes de Joaquim da Silva Prado como, por exemplo, uma possível simpatia aos aquilombados, ou mesmo as respostas não dadas ao presidente da Província. 
cionado no documento, Joaquim da Silva Prado tinha escravos e esses precisavam ser alimentados.

Nossas suspeitas aumentam quando arrolamos uma correspondência de tempos antes, 19 de agosto de 1829, do vice-presidente da Província de Mato Grosso Jerônimo Joaquim Nunes ao Capitáo Joaquim da Silva Prado lhe informando de uma expedição que estava sendo organizada e enviada contra os índios de Mato Grosso e este teria que dar os devidos suportes e encaminhar o "trilhador" para o rumo dos "gentios". Todavia, o envolvimento do Capitão, novamente se dá, pois, os "gentios que fizerão hostilidades na tropa do capitão José Coelho Lopes" estão "na vizinhança do engenho do referido capitão". 8

Isto posto, podemos perceber que a implicação do capitão nas expedições pode se dar não por conta de incômodos, embora os índios e negros já lhe tenham causado segundo os discursos do Presidente e Vice, mas por conta da proximidade de suas terras com o quilombo ou mesmo com a localização dos povos indígenas - tratados como pragas que "infestão a estrada"?

Além disso, numa outra correspondência deste mesmo livro encontramos o vice-presidente da Província André Galdiz Luz, em meados de 13 de fevereiro de 1830, pedindo providências ao Capitão Joaquim da Silva Prado acerca dos indígenas e dizendo que estava enviando mais homens para expedição ${ }^{10}$. À vista disso, nos surge outra inquietação: porque o Capitão estava sendo cobrado por providências?

Para tal questão, é cabível enxergar que as ordens anteriores não estavam sendo cumpridas em sua totalidade, ou então as expedições poderiam estar fracassando, quiçá, por conta do náo apoio empenhado do Capitão e apenas este estar servindo de apoio logístico as empreitadas, como acusa o Tenente José Theodoro de Araújo ao descrever os detalhes da bandeira que seguia para destruir os "gentios". O Tenente aponta os caminhos que a expedição deveria seguir passando por fazendas e paragens que lhes servia de reforço. Nessas paragens se incluía a fazenda do Capitão Joaquim da Silva Prado. Assim, dizia o Tenente:

A marcha deve ser com cautela indagando as diferentes braças, que se encontrarem a direita, e a esquerda do dito rio águas acima, porque nestas paragens já é morada dos gentios, chegando porém a expedição ao lugar em que já não haja navegação para as canoas, e que não tenha tido encontro do gentio na sua marcha até aquele ponto mandará o Sr. Tenente José Theodoro de Araújo procurar dali a barra do rio Parnahiba, que desagoa no de S. Lourenço, e conhecida que seja mandará uma escolta de 30 a 40 homens dos mais suficientes seguir pela margem do Parnahiba até o Alecrim, e dali até o Engenho do Capitão Joaquim da Silva Prado aonde receberá algum municio, que lhe for preciso, voltando a reunir-se e ao alojamento. ${ }^{11}$

8 Livro 21 - EST. 05. 7407. Registro de Correspondência da Presidência da Província às Autoridades Provinciais (1829 a 1831). Cuiabá, 19 de Agosto de 1829 - Jerônimo Joaquim Nunes.

$9 \quad$ Livro 21 - EST. 05. 7442. Registro de Correspondência da Presidência da Província às Autoridades Provinciais (1829 a 1831). Instruçóes ao Tenente José Theodoro de Araújo na diligência que foi contra os índios.

10 Livro 21 - EST. 05. 7424. Registro de Correspondência da Presidência da Província às Autoridades Provinciais (1829 a 1831).

11 Livro 21 - EST. 05. 7442. Registro de Correspondência da Presidência da Província às Autoridades Provinciais (1829 a 1831). Instruçóes ao Tenente José Theodoro de Araújo na diligência que foi contra os índios. Cuiabá, 14 de julho de 1830 . 
Levando em consideração o arrolamento desses documentos, juntamente com uma análise heurística, estamos tentando sondar o envolvimento ou mesmo alguma forma de simpatia do Capitão Joaquim da Silva Prado aos agentes negros e indígenas da Província de Mato Grosso nos oitocentos. Nesse sentido, ansiamos por buscar respostas nessas fontes, pois, muitas vezes elas se cruzam, mesmo que indiretamente.

Mesmo que não encontremos as respostas, podemos buscar entender o porquê elas não se configuram como respostas, ou melhor, porque muitas vezes são silenciadas quando perguntadas sobre tais questóes, por exemplo. Assim, náo queremos julgar os acontecimentos, ou a figura do Capitão, pois, não cabe ao historiador julgar (BLOCH, 2001), mas sim compreender os acontecimentos históricos à luz de seu passado, e com as questóes que lhe incomodam no presente, almejando tocar a vivência subjetiva dos sujeitos, sejam eles considerados ilustres ou não.

Assim sendo, não seria utópico ou espantoso o Capitão Joaquim da Silva Prado simpatizar, mesmo que indiretamente, com os negros, negras e povos indígenas. Azevedo (1987) nos aponta que essa prática ocorria em outros lugares do Império, em sua abordagem na Província do Maranhão oitocentista ao observar que:

Alguns quilombos da região de expansão algodoeira do Maranhão cultivavam também este produto e vendiam-no aos fazendeiros, recebendo em troca ferramentas, armas e tecidos. Os proprietários, por sua vez, aceitavam estas relaçóes de comércio e, fosse por medo dos negros ou por simpatizar com tais vizinhos (AZEVEDO, 1987, pp.45-46).

Estes atos de simpatia/negociação iam totalmente contra a legislação e o padrão social estabelecido de relação entre brancos e negros, pois as autoridades Provinciais temiam que esses espaços se transformassem em uma "sociedade na sociedade" (AZEVEDO, 1987). Assim, se articulavam as coerçóes a estes espaços - o que náo impedia que novos quilombos fossem construídos a partir da destruição de outros.

Michel Foucault (1999) salientou que desde o século XVII se criaram fortes padróes de ordem no Ocidente estabelecidos a priori aos sujeitos, podendo ser entendidos como ordens existentes dentro da cultura de uma sociedade que, segundo o autor, cuidam de manter o controle e reprender qualquer ameaça de desordem, pois a própria desordem prenuncia um princípio de ordem.

Partindo dessa reflexão, o que podemos compreender sem dúvidas, é o interesse do governo em manter a ordem e, para isso, seria necessário "destroçar" os quilombos, capturar os negros e negras fujóes para devolvê-los aos seus senhores, aniquilar os perigos que estes espaços causam a sociedade e, sobretudo, liberar as ameaças que rondavam as estradas com as rotas de aquilombados (GOMES, 2005). De tal modo, apreendemos que os vários quilombos de Mato Grosso enfrentavam amplas coerçôes das Bandeiras e outras empreitadas, isso porque segundo Volpato, "vencendo quilombos, o governador vencia um inimigo antigo e temido" (1996, p.225).

A fala do Presidente da Província Estevão Ribeiro Resende é bem sugestiva quanto a isso:

Convemfazel-os [os quilombos] bater e destruir. Estas reuniôes de escravos fugidos são más não só pelos prejuízos que occasionão a seos donos, mas também pelo perigo da segurança da vida e 
fasenda dos póvos e finalmente pelo alento que dão a fuga de outros escravos a quem oferecem guarida $^{12}$ (Apud Volpato, 1993, p.186).

Todavia, mesmo com os mandos para destruição de quilombos "os senhores de escravos e as autoridades em Mato Grosso, tanto no período colonial como na etapa nacional, tiveram que conviver com os quilombos" (VOLPATO, 1993, p.184). Além do medo dos quilombos, somamos aqui as contribuiçóes de Azevedo que nos alerta para as fugas dos negros e negras tendo como ponto final os quilombos. No entanto, até chegarem a esses espaços, precisavam sobreviver e, para tanto, muitos "saqueavam cidades e vilas" (AZEVEDO, 1987, p.206).

Além das cidades e vilas assaltadas pelos negros fujōes, as fazendas, sítios e pequenas propriedades também eram assaltadas por esses e pelos quilombolas. Na região do Cuiabá o medo tomava conta dos moradores, pois

Os habitantes do quilombo de rio manso se aproveitavam da melhor forma que puderam. A condição dos habitantes das redondezas era de medo, e as guarniçóes militares não se encontravam em situação de socorrer os sitiantes. Conhecedores das vantagens de que desfrutavam, os quilombolas procuravam usufruir delas o máximo que podiam (VOLPATO, 1993, p.187).

Muito por conta desse medo/pânico e também pela ameaça real que rondava as estradas, as autoridades se viam pressionadas a andarem armadas e sempre alertas para qualquer sinal de desordem. Podemos notar isso desde o Mato Grosso colonial, contexto em que,

[...] como huns e outros pelas estradas, que costumaô cursar [experimentam] [?] silladas de seos inimigos esperando-os para os matarem por serem todas cheyas de matos, a donde se escondem fazendo o mesmo os escravos fugidos, que unidos em Quilombos roubam, e mataódespensareis com alguns dos sobre dittoseviandantes [...] trazerem pistollas nos Coldres para se defenderem [...] poderaó levar pelas estradas aonde se fazem precizas para a sua deffença. ${ }^{13}$

Com tais características, vemos uma Província que como as demais, travava incessantes batalhas contra os negros e negras, povos indígenas, ou a qualquer pessoa que se aliasse a esses "criminosos" pelo olhar imperial. Nesse sentido, as leis e os códigos de conduta existiam e deviam ser seguidos, porém observamos escravos que lutaram por seus espaços de autonomia dentro dessa sociedade escravocrata e a formação de quilombos é um afronte tremendo aos homens da lei.

Sem dúvidas, tratar da história desses agentes históricos é perceber ainda uma contravenção do mando senhorial que lhes era imposto, é apreender o desmando, o afronte, mostrar a resistência, nem que para isso suas vidas fossem levadas. Por fim, é olhar que esses sujeitos têm vozes e elas precisam ser escutadas, interpretadas e escritas, pois o historiador, diferente do cronista, deve cuidar de explicar esses episódios da história (BENJAMIN,

12 Discurso do Presidente Estevão Ribeiro Resende, 1840.

13 Provisão expedida pelo Conselho Ultramarino ao Governador Rodrigo Cezar em 13 de agosto de 1725 - sobre se aprovar haver dado licença a algumas pessoas para trazerem pistolas pelos caminhos, e permitir continuem náo se levando emolumentos, as partes pelos despacho[s]. In: Documentos Régios: 1702-1748: Códice n. 1 da Superintendência de Arquivo Público de Mato Grosso / estudo introdutório Maria de Fátima Costa; transcrição paleográfica Luzinete Xavier de Lima. - Cuiabá, MT: Entrelinhas, 2013. 
1987). E nestes episódios da história, as roças também são protagonistas, dado que, a partir delas os quilombolas retiravam a existência e os mecanismos de troca, por exemplo.

Porquanto, se faz necessário explorar ainda mais essa temática, uma vez que a entendemos como pedra angular na vida efetiva dos quilombos. Isso porque os quilombos no Brasil, segundo Gomes (2015), não tiveram um caráter de isolamento à sociedade, eles estiveram longes e presentes ao mesmo tempo; muitos se formando aos redores das cidades e outros mais afastados, mesmo assim, não os impedia de ter contatos direitos e indiretos com a sociedade. E, sem dúvidas, a "economia quilombola" era o elo de ligaçáo entre quilombos e sociedade (GOMES, 2015, p.19).

\section{UMA BREVE ANÁLISE DAS ROÇAS NOS QUILOMBOS E EM SEUS ARREDORES}

Entendemos que a roça é "o local destinado à produção de alimentos: arroz, feijão, milho, mandioca" (SECRETO, 2005, p.408). Todavia, "o termo roça procede da operação que antecede a preparação do terreno para o cultivo, o roçado. O roçado é a operação realizada quando se trata de derribar a mata" (SECRETO, 2005, p.409). Está prática de derrubada da mata para o cultivo é utilizada desde as primeiras décadas de colonizaçáo lusa na América (LINHARES, 1979). Porém, não é exclusiva dos senhores de terras já que os quilombolas também limpavam o mato para cultivar roças. Assim, vemos que a prática de cultivar roças também transcendia aos espaços de dominaçáo senhorial, outrossim estavam muitas vezes nele imerso, como observado por Reis e Silva (1989) ao discutirem a na brecha camponesa, por exemplo. Neste viés, percebemos que os negros e negras que fugiam para quilombos lançavam mão de cultivar seus gêneros alimentícios nesses espaços, tanto para autossuficiência quanto para comercialização/troca.

Ao analisar a correspondência ${ }^{14}$ enviada a Joaquim da Silva Prado em 1839, percebemos que o Presidente da Província Estevão Ribeiro de Rezende cuidando de recomendar os pontos principais a serem observados na rotina do quilombo para facilitar a destruição do mesmo, descreve algumas práticas que os escravos fugidos presentes naquele quilombo realizavam, dentre elas a derrubada e queimada de matos para plantarem suas roças. ${ }^{15}$

Por esse ângulo, podemos perceber evidências históricas que nos proporcionam pensar a existência de roças nos quilombos, sobretudo a função que elas desenvolviam na vida efetiva dessas organizaçóes, fornecendo gêneros alimentícios, especialmente quando se atravessava um período de luta contra toda e qualquer investida do poder provincial, sendo que era arriscado procurar comida pela mata ou ir até os rios, sob ameaça real, por exemplo. Flávio Gomes (2015) ainda nos alerta que por conta da escassez de alimentos no

\footnotetext{
14 Província de Mato Grosso: registro de correspondência oficial com o interior da província, 1838 - 1839. Arquivo Público do Estado de Mato Grosso do Sul, doc.56 e.5, 4393.

15 Neste momento, agradecemos as contribuiçóes da Prof. a Maria Celma Borges em seu trabalho "As roças e as suas frestas em Mato Grosso: entre a Colônia e o Império", pois, foi a partir deste que tivemos contato com essa fonte histórica, bem como à algumas discussôes aqui lançadas.
} 
período, as expediçóes que iam contra os quilombos tinham a intenção de destroçá-los, bem como se apropriar de suas produções agrícolas. Assim, podemos, mais uma vez, notar a expressão que a agricultura quilombola representava ora fornecendo alimento e moeda de troca para os quilombolas, ora sendo fruto de desejo de autoridades provinciais.

Ainda nessa correspondência notamos a presença de plantaçóes e roças aos redores do dito quilombo e pelo descrito entendemos que são pequenos espaços de cultivos, "[commodidades] necessárias para a subsistência”. ${ }^{16}$ Mas, não por serem pequenas deixaram de ser vitais a aqueles moradores, pois lhes fornecia o sustento diário, ou mercadoria para conseguir suprimentos que necessitavam. Além disso, esses pequenos proprietários de sítios e chácaras, poderiam criar vínculos com os escravos aquilombados, gerando "redes de proteção e solidariedade" (GOMES, 2005, p.154).

Ribeiro e Pereira (2009) assinalam que os quilombolas também comercializavam suas mercadorias no âmbito das tavernas e no núcleo citadino. No caso de Mato Grosso oitocentista, no âmbito desse estudo, ainda não encontramos vestígios de negociações diretas entre quilombolas e núcleo citadino, o que percebemos a partir dos relatos, muito de forma subjetiva pelos documentos, é que ocorriam possíveis negociações com os fazendeiros e a criação das redes de solidariedade para poderem se proteger e se fortificar. Portanto, iremos continuar vasculhando as correspondências, ofícios, cartas, enfim, em busca dessas evidências históricas que nos ajudam a pensar essa negociaçáo direta entre quilombolas e comerciantes urbanos.

Para tanto, também podemos considerar os apontamentos de Alencastro (1997) quando diz que o trajeto do ouro vindo de Goiás e Mato Grosso contribuíram para o surgimento de fazendas, vilas e roças, estas últimas que tanto nos interessam. Assim, iremos apreender essas fontes que cuidam do referido trajeto com o intuito de encontrar narrativas sobre as roças. Nesse sentido, este trecho do trabalho mesmo que de maneira breve, tentou lançar luz a uma discussão que precisa ser mais latente para, desta forma, entendermos melhor como os negros aquilombados utilizavam o mecanismo dos roçados para além da sua autossuficiência.

Por fim, mas não menos importante, levamos em consideração os apontamentos de Borges (2015) no que concerne aos avanços no campo de pesquisa sobre as roças e os roceiros, porém, ainda pequenos se comparado com a dimensão que esses espaços e agentes representaram na História de nosso país. No entanto, todo avanço no sentido de narrar a história dessas pessoas é bem-vindo, uma vez que "o cultivo das roças naquele momento histórico indica a produção da vida” (BORGES, 2015, p.15).

\section{ALGUMAS BREVES CONSIDERAÇÕES}

Após as reflexões expostas neste trabalho, assumimos logo de início, a dívida insolvente que o historiador tem para com o conhecimento histórico na medida em que não

$16 \quad$ Idem. 
conseguimos reconstruir o passado, pois ao menos sabemos se ele já esteve construído, podemos nos aproximar, por meio dos vestígios e dos documentos do que, de alguma forma, um dia foi (RICOEUR, 1997).

Destarte, investigar os quilombos e as roças é sempre um desafio, porém é instigante, uma vez que encontramos contradiçôes nas fontes, ora nos guiando a um entendimento sobre tal acontecimento, ora desmontando todo esse entendimento que construímos com perguntas. Assim, acabam gerando o desejo do saber e as inquietaçóes se configuraram como pedras angulares nessa empreitada de apreender os quilombos e suas roças.

No bojo desse trabalho pouco podemos concluir, mas muito podemos refletir. Nos resta ainda muitas inquietaçóes no que diz respeito a vida efetiva dos quilombos e quilombolas ligados a Província de Mato Grosso oitocentista. Assim, este trabalho foi um compilado de algumas delas e um prenúncio que podem surgir mais. 


\section{REFERÊNCIAS}

ALESCASTRO, Luiz Felipe de. Vida privada e ordem privada no Império. In: História da vida privada no Brasil: Império. (Org) ALESCASTRO, Luiz Felipe de. São Paulo: Companhia das Letras, 1997.

AZEVEDO, Célia M. M. de. Onda negra, medo branco: o negro no imaginário das elites - século XIX. Rio de Janeiro: Paz e Terra, 1987.

BENJAMIN, Walter. Magia e técnica, arte e política: ensaios sobre literatura e história da cultura. In: Obras escolhidas; volume 1. Tradução: Sergio Paulo Rouanet. $3^{a}$ Ed. São Paulo: Editora Brasiliense, 1987.

BLOCH, Marc. Apologia da História ou o ofício do historiador. Rio de Janeiro: Jorge Zahar Ed. 2001.

BORGES, Maria Celma. As roças e as suas frestas em Mato Grosso: entre a Colônia e o Império. (NO PRELO)

FOUCAULT, Michel. As palavras e as coisas: uma arqueologia das ciências humanas. Tradução Salma Tannus Muchail. — 8a ed. — São Paulo: Martins Fontes, 1999.

GOMES. Flávio dos Santos. A hidra e os pântanos:mocambos, quilombos e comunidades de fugitivos no Brasil, (séculos XVII-XIX). São Paulo: Editora UNESP: Editora Polis. 2005.

. Quilombo. In: Márcia Motta (Org.) Dicionário da terra. Rio de Janeiro: Civilização Brasileira, 2005.

LINHARES, Maria Yedda. A limitação do mercado interno: colônia e metrópole. In: História do abastecimento: uma problemática em questão (1530-1915). Brasília: Binagri, 1979.

SECRETO, Veronica. Roça. In: Márcia Motta (Org.) Dicionário da terra. Rio de Janeiro: Civilização Brasileira, 2005.

SYMANSKI, Luis Claudio Pereira. Quilombos. In: JESUS, Nauk Maria de (org.). Dicionário de História de Mato Grosso: período colonial. Cuiabá/MT: Carlini\&Caniato, 2011.

SZACHI, Jerzy. As utopias. Rio de janeiro: Paz e Terra, 1972.

REIS, João José; SILVA, Eduardo. Negociação e conflito - A resistência negra no Brasil escravista. São Paulo: Companhia das Letras, 1989.

REIS, João José; GOMES, Flávio dos Santos. Liberdade por um fio: história do quilombo no Brasil. São Paulo: Companhia das Letras. 1996.

RICOEUR, Paul. Tempo e narrativa. Tomo III. Trad. Roberto Leal Ferreira. Campinas: Papirus, 1997.

RIBEIRO, Gladys Sabina. PEREIRA, Vantuil. O primeiro Reinado em revisão. In: O Brasil Imperial, volume I: 1808-1831. (Orgs.) Keila Grinberg e Ricardo Salles. Rio de Janeiro: Civilização Brasileira, 2009. 
VOLPATO, Luiza Rios Ricci. Cativos do sertão - Vida cotidiana e escravidão em Cuiabá em 1850-1888. Sáo Paulo: Editora Marco Zero, Cuiabá: Editora da Universidade Federal de Mato Grosso, 1993.

. Quilombos em Mato Grosso-Resistência negra em área de fronteira. In: Liberdade por um fio: história dos quilombos no Brasil.São Paulo: Companhia das Letras. 1996.

WISSENBACH, Maria Cristina Cortez. Sonhos africanos, vivências ladinas: escravos e forros em São Paulo (1850-1880). São Paulo: Editora Hucitec, 1998.

Recebido: $15 / 5 / 2017$

Aceito: 10/7/2017 